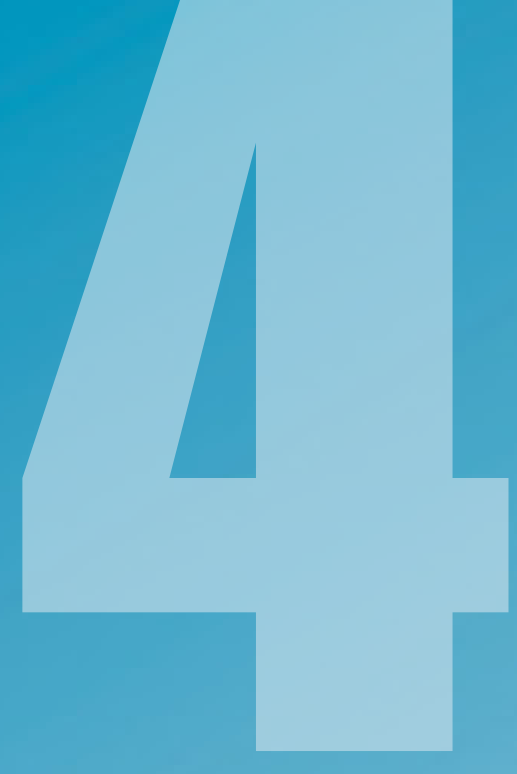

ÁMBITOS

REVISTA

INTERNACIONAL

DE COMUNICACIÓN

$N^{\circ} 46$

EDICIÓN OTOÑO

2019

ISSN: 1139-1979

E-ISSN: 1988-5733

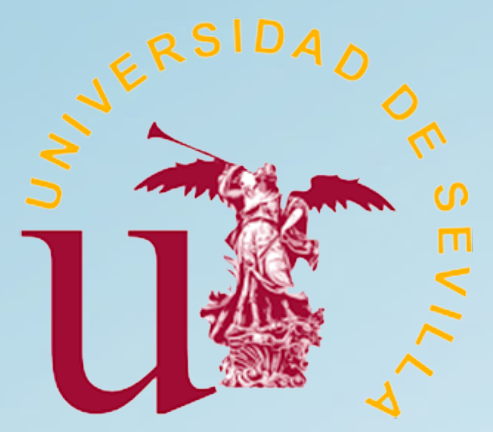




\section{ÍNDICE}

MONOGRAFICOS MONOGRAPHS

Presentación Monográfico. Comunicación emergente. Experiencias para el cambio social

Dra. Nereida López Vidales

Los formatos de televisión más consumidos por los jóvenes: telerrealidad y empoderamiento de la audiencia

Most consumed televisión formats by young people: real TV and the empowerment of the audience Nereida López Vidales, Leire Gómez Rubio, Elena Medina de la Viña

Nuevas herramientas, viejas costumbres El Contenido Generado por los Usuarios sobre el cambio climático en YouTube

New tools, old habits User Generated Content about climate change on YouTube

David Vicente Torrico

Tratamiento periodístico de personas LGTBIQ+ refugiadas: estudio de caso sobre Pride Barcelona 2018

Journalistic treatment of LGTBIQ+ refugees: case study on Pride Barcelona 2018

Hadriel Theodoro, Amparo Huertas Bailén

Tiempo Muerto, estudio de caso de un proyecto transmediático para la consecución de competencias universitarias

Tiempo Muerto, case study of a transmediatic project for the achievement of university competences Jose L. Carreño Villada, Miguel Ángel Díaz Monsalvo

Los universitarios millennials: uso de redes sociales y relación con las marcas

University Millennials: use of social media and engage with brands

Pedro Pablo Marín Dueñas, Esther Simancas González

Ali Ferzat: De la caricatura comunicativa en papel a la caricatura activista en los medios digitales

Ali Ferzat: From political cartoons in papers to political cartoons in digital media

Salud Adelaida Flores Borjabad

Direito à informação e literacia midiática: Reflexões sobre a questão do acesso

Right to information and media literacy: Reflections on the question of acce

Christiane Delmondes Versuti 
Eficacia de los influencers como recurso publicitario en la estrategia de los anunciantes locales Efficacy of influencers as an advertising resource in the strategy of local advertisers

Isabel Iniesta-Alemán

As redes sociais como ferramenta de marketing em instituições de ensino superior no Brasil Social networks as a marketing tool in higher education institutions in Brazil

Alcino Ricoy JR, Rogério Eduardo Rodrigues Bazi

Estudio sobre la conceptualización y el tratamiento informativo de la violencia de género en la prensa digital cubana

Study about the conceptualization and information treatment of gender violence in the Cuban digital press

Regla Ismaray Cabreja Piedra, Karina Escalona Peña

\section{ARTÍCULOS ARTICLES}

Uso de Twitter durante los debates electorales televisados en los comicios andaluces de 2018 The use of Twitter during the televised electoral debates in the 2018 Andalusian elections Julia Fontenla Pedreira, Erika Conde Vázquez, Carmen Máiz Bar

Quem averigua as notícias, os algoritmos ou jornalistas? A lógica crítica de C. S.

Peirce como processo de identificação de uma Fake News

Who checks the news, algorithms or journalists? The critical logic of C. S. Peirce as a

process for identifying a Fake News

Adelino de Castro Oliveira Simões Gala, Vania Baldi, Universidad de Aveiro

\section{RESEÑAS REVIEWS}

Nuevo ecosistema comunicativo digital: El consumidor

Juan Carlos Figuereo Benítez

Corpus toponímic de Beniarrés

Bianca Sánchez-Gutiérrez

The Future Computed. La inteligencia artificial y su papel en la sociedad y Pulsa actualizar. La aventura de redescubrir el alma de Microsoft y concebir un futuro mejor para todos 


\title{
Quem averigua as notícias, os algoritmos ou jornalistas? A lógica crítica de C. S. Peirce como processo de identificação de uma Fake News
}

\author{
Who checks the news, algorithms or journalists? The critical \\ logic of C. S. Peirce as a process for identifying a Fake News
}

Adelino de Castro Oliveira Simões Gala, Universidad de Aveiro, Departamento de Comunicação e Arte, DigiMedia - Digital Media and Interaction Centre, Campus Universitário de Santiago 3810-193, Portugal adelinogala@gmail.com | Orcid: https://orcid.org/0000-0003-2707-1610

Vania Baldi, Universidad de Aveiro, Departamento de Comunicação e Arte, DigiMedia - Digital Media and Interaction Centre, Campus Universitário de Santiago 3810-193, Portugal vbaldi@ua.pt | Orcid; https://orcid.org/0000-0002-7663-3328

DOI: http://dx.doi.org/10.12795/Ambitos.2019.i46.13

\begin{abstract}
Resumo
O presente artigo pretende analisar o cenário contemporâneo da comunicação digital nos seus aspetos mais problemáticos para o mundo da informação. A desordem informacional, suportada por dispositivos computacionais, é perspetivada a partir da dimensão epistemológica por ela levantada e através das formas de raciocínio que nela atuam. Neste sentido serão utilizadas as categorias lógicas de dedução, indução e abdução elaboradas pelo semiólogo Charles Sanders Peirce. Os sistemas
\end{abstract}


computacionais são enquadrados como sistemas sociotécnicos dentro dos quais é necessário saber distinguir entre processos algorítmicos editados por engenheiros e sistemas automatizados de resposta e difusão. As formas de aprendizagem e execução promovidas por máquinas inteligentes são assim questionadas. Conforme tal distinção alcança-se uma perspetiva crítica sobre os conteúdos produzidos na infoesfera capaz de enquadrar os níveis de intervenção cultural (e ideológica) dentro dos processamentos automatizados.

\section{Abstract}

This article aims to analyze the contemporary scenario of digital communication in its most problematic aspects for the information world. The informational disorder, supported by computational devices, is viewed from the epistemological dimension raised by it and through the forms of reasoning that act on it. In this sense will be used the logical categories of deduction, induction and abduction elaborated by semiologist Charles Sanders Peirce. Computational systems are framed as sociotechnical systems within and it is necessary to distinguish between algorithmic processes edited by engineers and automated response and diffusion systems. The forms of learning and execution promoted by intelligent machines are thus questioned. As such distinction is reached a critical perspective on the contents produced in the infosphere capable of framing the levels of cultural (and ideological) intervention within the automated processing arises.

Palavras-chave: Pós-verdade, Algoritmos, C. S. Peirce, Lógica Crítica, Raciocínios Sociotécnicos

Keywords: Post-truth, Algorithms, C. S. Peirce, Critical Logic, Machine Learning, Sociotechnical Reasons

\section{INTRODUÇÂO}

Nos tempos atuais as notícias são produzidas, consumidas e veiculadas numa escala de processamento, memorização e partilha sociotécnica que ultrapassa qualquer momento anterior vivido pela humanidade. Deve-se à intermediação dos sistemas computacionais, regidos por específicos algoritmos, que se apresentam como generosos propulsores de desintermediação cultural e que atuam pelas plataformas e serviços digitais como Facebook, Twitter, Instagram, Whatsapp etc. Nesse ambiente os agentes produtores de notícias e opiniões (e confusão entre as duas coisas) se multiplicam, determinando processos de desinformação e desordem cognitivo. 
O espaço digital se configura progressivamente como um território de conquista, com conteúdos noticiosos sempre mais incertos e escorregadios, onde as emoções e visões sobre a realidade se misturam e se aproximam das ficções. As Fake News, assim, se tornam como "armas" para uma guerra entre narrativas sobre factos teoricamente reconhecíveis como tais por parte de todos, mas ressignificados como representantes de "realidades alternativas". Assim, o desejo de acreditar apenas em uma versão da realidade, assim como num conteúdo não verificado, precisaria ser travado por um olhar crítico sobre a facciosidade e os males que estes poderiam causar.

Esta dissonância entre narrativas afeta também as polarizações entre notícias de cariz científico e conspirativo, onde manifesta-se uma viralização de conteúdos anticientíficos. Também os conhecimentos estabelecidos e as competências consolidadas, portanto, ficam reféns de uma lógica opositiva assente na descrença apriorística contra o que tradicionalmente era considerado ser oficial e objetivo. Os âmbitos das notícias, das informações e das ciências ficam assim desafiados a experimentar novas formas de apresentar, analisar, assinalar e divulgar o que parece ameaçar a sua credibilidade.

A lógica do pensamento crítico, como destacado também pelo trabalho epistemológico de Peirce, é a pedra fundamental no combate e na prevenção da distorção dos factos e dos conhecimentos estabelecidos. Agora trata-se de ter em conta como tal senso crítico deve cada vez mais instalar-se também no âmago dos softwares que gerem e produzem informações em rede.

\section{UMA NOVA DESORDEM INFORMACIONAL}

Em 2016, o termo "pós-verdade" (post-truth) foi escolhido como palavra internacional do ano pelo Dicionário Oxford (Oxford Dictionaries). O adjetivo denota "circunstâncias nas quais factos objetivos são menos influentes na formação da opinião pública do que apelos à emoção e à crença pessoal". O conceito de pós-verdade aparentemente não é novo. Já havia sido utilizado por Steve Tesich na revista The Nation 1992 (Berthon \& Pitt, 2018) para se referir ao escândalo do Irão e da Guerra do Golfo, lamentando que "como povos livres, decidimos que queremos viver em algum mundo de 'pós-verdade'". Santaella (2018, p.49) aponta para dois sentidos que albergam na ideia de "pósverdade": o significado "depois que a verdade tenha se tornado conhecida"; e o significado inaugurado pelo artigo de Tesich, a saber, o facto de que a verdade se tornou irrelevante. No seu sentido expandido, o prefixo "pós" não significa apenas "depois de um evento ou situação específica" como, por exemplo, na expressão "pós-guerra", mas também implica "um tempo em que um conceito se tornou irrelevante ou sem importância." Conforme Harari (2018, p.271) "parece que, de facto, estamos vivendo em uma terrificante era da pós-verdade, quando não apenas incidentes militares, mas histórias e nações inteiras podem ser falsas". O historiador acrescenta ainda que o

Ámbitos. Revista Internacional de Comunicación | ISSN: 1139-1979 | E-ISSN: 1988-5733, №. 46. (2019) 
"Homo sapiens é uma espécie da pós-verdade, cujo poder depende da criação e da crença em ficções."

Em 2017, os editores do Oxford English Dictionary selecionaram o termo fake news como a palavra do ano, depois de seu uso ter aumentado em 365\% nos 12 meses anteriores (Bolton \& Yaxley, 2017). E são as notícias falsas que se transformaram em verdadeira indústria de alta produtividade, destacadamente nos medias sociais digitais, tornando-se matéria prima para o terreno da pós-verdade. No contexto político estas buscam colocar os nervos à flor da pele e causar tumulto valendo-se da descentralização da informação, que a internet distribui por muitos canais de comunicação diferenciados, alternativos e independentes, sem marcar seus compromissos com a informação oficial.

Ao analisar os principais jornais durante os grandes confrontos do século XXI, descobrese com moderada clareza que mentiras e verdades sempre coexistiram (Marcos Recio, Sánchez Vigil, \& Olivera Zaldua, 2017). Tal contexto, ampliado e renovado pelas novas plataformas digitais que fragmentam e fecham os diferentes internautas em grupos autorreferenciais (echo chambers), tem levado ao extremo a incomunicação entre quem tem convenções diferentes e a fabulação das crenças, como no caso dos desacordos sobre a crise climática ou até as aberrações como aquelas da terra plana.

De facto, como foi assinalado pela politóloga Anne Pluta no seu Trump Supporters Appear to Be Misinformed, Not Uninformed (2016), é preciso distinguir entre os tipos de públicos e as situações em que esses públicos sem contexto atuam: "os cidadãos desinformados não dispõem de qualquer informação, enquanto os que estão mal informados dispõem de informação que contraria os dados conhecidos e a opinião dos especialistas". ${ }^{1}$

Estamos, portanto, perante uma peculiar sobreposição de conflitos desencadeados por um discurso público radicalizado e fragmentado, onde os confins entre propaganda, alteração da realidade, conhecimento estabelecido e invenção de factos parecem evaporar-se, desafiando uma construção da realidade baseada em notícias e comentários virais, constantemente percecionados como suspeitos e acusados de serem manipulados. Como afirma Tom Nichols no seu A morte da Competência. Os Perigos da Campanha Contra o Saber Estabelecido:

Pensava-se que anos de melhoria do ensino, o acesso facilitado aos dados, a explosão das redes sociais e remoção dos obstáculos à participação no debate público iriam melhorar a nossa capacidade de deliberar e decidir. Pelo contrário, parece que estas mudanças tornaram tudo pior. Qualquer informação pública sobre qualquer assunto descamba numa guerra de trincheiras, em que o objetivo mais importante é o de provar que a outra pessoa está enganada (Nichols, 2018, 
p. 63).

Conforme Santaella (2018, p.33), as Fake News carregam as características centrais de desinformação, desconfiança e manipulação. Através da capacidade atual de armazenagem, processamento e distribuição de informações pela Internet, a comunicação digital se tornou também personalizada. Cada entidade ou objeto que atua online tem as suas ações catalogadas em uma base de dados. Os modelos estatísticos associados às teorias comportamentais (ver, por exemplo, McCrae, 1991 e Gala, 2015) podem criar uma predição comportamental dessas entidades. Isso permite a formatação e envio de conteúdo de acordo com a presumida personalidade dos indivíduos refletidas pelos registos do histórico online, aumentando o poder de indução emocional desses conteúdos produzidos à medida.

Santaella (2018, p.34-36) aponta que as Fake News podem ser classificadas conforme sua capacidade de prejudicar aspetos cognitivos. As paródias são as de menor grau, pois são produzidas para o riso e o entretenimento, desde que não sejam preconceituosas. Existem também as notícias caça cliques (clickbait), com o intuito de captar e monetizar notícias culturalmente pouco relevantes. Existem ainda as notícias híbridas, que misturam matéria séria com sensacionalismos, por exemplo, falsos contextos associados a conteúdo genuíno. Outro destaque são os conteúdos impostores, afirmações atribuídas a pessoas que não as fizeram de facto. Todas estas acarretam problemas, mas a situação se agrava quando se adentra na engenharia das notícias falsas com apoio computacional na produção e disseminação das mesmas. Esta última projeta negatividade de modo subtil e ao mesmo tempo intenso, "explorando o campo da vagueza e das lacunas cognitivas inerentes a processos cognitivos potencialmente desprovidos como os dos humanos" (ver Santaella, 2018, p.68).

A chamada information disorder espelha uma falta de atenção e regulamentação sobre a qualidade dos conteúdos noticiosos e o modelo de negócio subjacente, acompanhando um clima político e cultural aparentemente cada vez menos disponível a uma reflexão aberta e ponderada sobre as várias questões sociais que marcam os desafios do nosso presente. Assistimos a um conjunto de debates, na esfera digital e política, que, frequentemente, carecem ou prescindem de referências concretas e lógicas na sua argumentação. Nesse cenário, parece pouco importante sustentar com factos e raciocínios fundamentados as tomadas de posição e as críticas sobre os problemas das sociedades contemporâneas.

A gramática das relações sociais, no cenário info-comunicacional pouco estruturado e racional, apresenta-se sob forma de contrastes polarizados entre grupos e/ou indivíduos que expressam sobre a mesma realidade interpretações muito diferentes ou, para utilizar um termo mais emblemático da atual semântica histórica, conceções da 
realidade "alternativas" e inconciliáveis, como se a realidade fosse algo factualmente sempre menos interessante, acessório e secundário (Sunstein, 2017).

Obviamente, aqui não se afirma que a realidade é passível de ser concebida como algo linear e monocromático e, portanto, simples de compreender. Pelo contrário, a sua ambivalência constitutiva é inevitavelmente terreno de conflitos entre várias maneiras de a querer representar e construir. Todavia, o que aqui está em jogo é a primazia adquirida pelas interpretações em detrimento dos factos, incluindo nesses os dados estatísticos, os resultados das investigações científicas, a manifestação objetiva e tangível dos acontecimentos (tanto históricos como naturais), os efeitos concretos das políticas económicas ou das jurisdições (tanto nacionais como internacionais).

Neste sentido, como referido, dar prioridade às interpretações, em vez de à verificação dos factos, remete para um ethos do conhecimento atrelado ao instinto e às emoções. Descobrimos assim, de uma forma nova e inesperada, que a sociedade da informação e do conhecimento tem gerado, também, um processo antirracionalista.

Estes, são problemas que a reforma e criação de algoritmos não consegue resolver por si só, como aponta Broussard (2018, p.144) em seu alerta contra o tecno-chauvinismo e as inúmeras falhas em projetos de software existentes em nossos tempos. O intenso combate que Google, Facebook, Twitter, Whatsapp e outras redes sociais e aplicativos de comunicação tem imprimido nesse campo, sem obter grande êxito em seus resultados, são exemplos da questão. O facto é que, conforme Santaella (2018, p.39), "os humanos são muito mais responsáveis pela disseminação das notícias falsas do que os robôs". A engenharia de notícias induz as fortes emoções humanas e acabam por transformar o mesmo em um mediador com alto potencial.

Como lidar com a questão das Fake News e os seus riscos para o campo científico e para o jornalismo? Santaella (2018, p.41), baseando-se nos estudos de Peirce, aponta o caminho do desenvolvimento do pensamento crítico.

\section{DAS CRENÇAS À EPISTEMOLOGIA ABDUTIVA}

Para Peirce (1877, p.1-2) estudar a lógica é importante para o desenvolvimento do raciocínio. Os escolásticos acreditavam que todo o conhecimento derivava de processos dedutivos provenientes de axiomas da autoridade. Existem ainda os idealistas, que acreditam que o conhecimento válido vem através de uma iluminação interior. $E$ os empíricos, que pautam sua noção suficiente de verdade em um procedimento experimental. O exemplo de Kepler deu uma importante contribuição ao pensamento astronômico e científico ao focar seus experimentos na observação do objeto Marte, para tentar inferir seu trajeto (CP 1.71-74, ver também Hoover, 1994, p.301), revelando a importância da abordagem empírica. Uma órbita acabou por ser

Ámbitos. Revista Internacional de Comunicación | ISSN: 1139-1979 | E-ISSN: 1988-5733, №. 46. (2019) 
descrita. Deste modo, os operadores presentes na lógica pela qual a natureza funciona são possivelmente correspondentes aos operadores presentes na mente lógica de quem raciocina de modo coerente. O objetivo do raciocínio é buscar essa coerência no desvelar das correspondências lógicas entre o continuum mente e matéria (ver Peirce 1877, p.3).

O ser humano é um animal lógico e tem uma tendência ao isolamento na realidade psicológica, ao universo dedutivo e imaginário, muitas vezes regidos pela esperança, a despeito das contradições da experiência. Este agrado persistente é aquele que nos leva a tendência de pensamentos habituais. O hábito é bom ou não segundo o sistema de crenças no qual ele está inserido. Produz conclusões verdadeiras a partir de premissas verdadeiras, mas sempre contingente a sua realidade de hábito. É o fio condutor do pensamento (ver Peirce, ibid. p. 4). Conforme aponta Santaella (2018, p.67), a lógica de Peirce não pretende tornar rígido a indeterminação e a incerteza, pois entende que a vagueza está no núcleo das línguas e das linguagens, sendo o local onde repousa o campo de possibilidades dos pensamentos. $E$ confrontar o hábito que repousa no campo da vagueza requer muito esforço.

Então, por que não adotar um ciclo retórico que melhor nos agrada e desprezar tudo o que nos incomoda? Por que não abraçar cegamente as fake news que nos interessam? Peirce $(1877$, p.6) possivelmente diria que se trata de uma abordagem aparentemente prática e direta e adotada por muitos. Mas existem situações onde essa atitude pode gerar inconvenientes, como negar o facto de que nossa digestão é feita por uma bomba gástrica dentro de nós, que se mal utilizada pode causar enfermidades. Segundo Santaella (2018, p.85), Peirce aponta para quatro métodos de fixação de crenças: tenacidade, autoridade, a priori e o método da ciência.

No primeiro as crenças são fixadas e evita-se por decisão própria a exposição a outras crenças que poderiam trazer dúvidas. O método da tenacidade levado ao extremo poderia levar à guerra dos particulares, pois se todos vivem dentro de uma bolha de crenças, acordos gerais são impossíveis. O segundo método é o da autoridade. Neste proíbe-se a adoção de outras crenças que não a oficial. Crenças particulares são reprimidas e apenas as premissas oficiais são válidas para guiar toda a razão. Se no primeiro caso existe a ignorância do geral pelo particular, neste segundo caso há uma ignorância do geral em relação ao particular. Tais métodos podem ser observados historicamente em regimes e doutrinas políticas, teológicas, aristocráticos, associações de classe, entre outras. No terceiro, o método a priori, a crença é fixada segundo a opinião vigente em grupos ou comunidades estando recorrentemente sujeita a modismos e gostos, caso dos metafísicos que nunca chegaram a um acordo do que seria uma filosofia primeira, funcionando como um pêndulo que variava entre o mais espiritual e o mais material.

Ámbitos. Revista Internacional de Comunicación | ISSN: 1139-1979 | E-ISSN: 1988-5733, №. 46. (2019) 
Para Peirce, todos esses métodos são intrinsecamente instáveis na medida em que a restrição externa que protege as crenças das dúvidas pode ser abalada no convívio social, no confronto com as crenças de outros povos ou pessoas, no confronto com os objetos da existência. Só seriam estáveis para um ermitão (ver Peirce, 1958, pp. 101112). Mas, a despeito dessa instabilidade das crenças em alicerces subjetivos, elas carregam um princípio geral, uma ideia de que há alguma permanência externa que move a crença. Essa permanência não pode ser causada exclusivamente por algo humano. São persistências externas, sobre os quais nossos pensamentos não têm nenhum efeito e que necessariamente afetam todos os homens. Assim, pelo método da ciência, se todos os homens seguirem um mesmo procedimento no estudo de um mesmo objeto, em qualquer hora, local e cultura, tenderão sempre a mesma conclusão. O método da ciência se autorrestringe, se regula e evolui de modo racional (ver Peirce 1877, p.11)

Charles S. Peirce construiu um sistema filosófico que contém discussões sobre os procedimentos cognitivos empregados pelas ciências. Seu trabalho se adicionou à discussão das abordagens dedutivas e indutiva, criando a lógica abdutiva, responsável pelo nascimento de novas hipóteses (ver Santaella, 2004). Vejamos em mais detalhes a lógica crítica. A Stanford Encyclopedia of Philosophy (BURCH 2001, in 3.Deduction, Induction, and Abduction) nos apresenta uma síntese dos três tipos de raciocínio.

a) (dedução) $O$ silogismo AAA-1 (Barbara): todos $M$ são $P$, todos $S$ são $M$, portanto todos $S$ são $P$ é um exemplo de dedução. Agora façamos uma ligação desse silogismo com um problema de amostragem. Vamos supor que ser $\mathrm{M}$ significa pertencer a uma dada população, por exemplo, uma bola numa população de bolas em alguma urna. Vamos supor que $\mathrm{P}$ seja uma característica de um membro dessa população, por exemplo, ser vermelho. E por fim vamos supor que ser $\mathrm{S}$ significa ser membro de uma amostra aleatória retirada da população. Desse modo o silogismo ficaria: todas as bolas numa urna são vermelhas, todas as bolas de uma amostra aleatória particular são retiradas dessa urna, portanto todas as bolas dessa amostra particular são vermelhas: um raciocínio necessário.

b) (indução) Vejamos o que acontece se trocarmos a premissa principal pela conclusão. Todos $S$ são $P$, todos $S$ são $M$, logo todos $M$ são $P$. Esse silogismo AAA-3 não é válido. Vamos considerar esse argumento em termos do problema de amostragem: todas as bolas numa amostra particular são vermelhas, todas as bolas dessa amostra aleatória particular são retiradas de uma urna, logo todas as bolas dessa urna são vermelhas. Encontramos assim um argumento que liga a amostra à população, para Peirce o principal significado da indução: um raciocínio provável.

c) (abdução) Por fim vejamos o que acontece se trocarmos a premissa menor pela conclusão: Todos $M$ são $P$, todos $S$ são $P$, logo todos $S$ são $M$. Esse é também um 
silogismo inválido AAA-2. Vejamos esse resultado em termos de teoria de amostragem: Todas as bolas numa urna são vermelhas, todas as bolas de uma amostra aleatória particular são vermelhas, logo todas as bolas dessa amostra aleatória particular são retiradas dessa urna. O que temos aqui não é um argumento que vai da população para a amostra (dedução), nem da amostra para a população (indução), é um argumento possível, distinto de ambos, que Peirce chamou de abdução. No caso, o facto das bolas serem vermelhas faz com que seja possível que elas pertençam a uma dada urna, mas não há nenhuma garantia a esse respeito.

Em termos lógicos dedutivos, tanto as inferências abdutivas quanto as indutivas estão incorretas. Entretanto, como posturas de raciocínios, ambas são relevantes. A abdução é o ato de encontrar um traço num fenômeno e a partir daí sugerir uma hipótese explicativa (Peirce, 1992, p. 186-199). A abdução pode ser ainda uma conjetura proveniente de interrogações não controladas, uma forma primitiva de inferência, mera possibilidade a ser testada. Segundo Blaug (1997, p.243), melhor seria se pudéssemos usar a palavra abdução para racionalizações não demonstradas. A abdução é o tipo de raciocínio através do qual a criatividade se manifesta não apenas na ciência e na arte, mas também na vida cotidiana. Não "apela para a razão", apenas sugere que algo "pode ser" (CP 5.171).

Como observa Hands (2001, p. 224), "abdução é uma noção relativamente frouxa de inferência”. É o juízo incerto que nasce sobre as bases de uma experiência passada e que se defronta com novos objetos no presente. Os raciocínios abdutivos, indutivos e dedutivos são, em última instância, irredutíveis entre si (CP 5.146), esses três tipos de raciocínio precisam trabalhar de modo combinado. A abdução, além de uma inferência lógica, está atada também a experiência percetiva do pesquisador. É no conceito de perceção que se situam as bases da epistemologia abdutiva. Segundo o Peirce: "os elementos de todo conceito entram no pensamento lógico pela porta da perceção e encontram sua saída pela porta da ação propositada; e aquilo que não puder mostrar seu passaporte nessas duas portas deve ser preso como não autorizado pela razão" (CP 1.202).

Peirce divide a perceção em três momentos: Percepto, Percipuum e Julgamento Percetivo. O Percepto: Percebemos aquilo que insiste e persiste em nossa presença, algo impositivo que não é criado por nossa mente, mas que se apresenta aos nossos sentidos como um existente a ser apreendido. Trata-se do elemento externo iniciador da perceção, que depende de elementos generalizadores e interpretativos para se fazer presente (ver Santaella, 2012, p. 111-138). Percipuum: é o modo como o percepto, este que está fora e bate à porta da perceção, é imediatamente traduzido pelo julgamento de perceção. O percepto passa necessariamente pelo filtro dos nossos sentidos para se apresentar ao julgamento percetivo (ver CP 7.643). O julgamento percetivo consiste em inferências lógicas gerais e simbólicas, que acomodam as interpretações em esquemas 
mais ou menos habituais. Nós só somos capazes de traduzir o percepto em julgamento de perceção porque estamos equipados com esquemas que processam e traduzem aquilo que está fora em algo que tenha semelhança com os demais tipos de juízos que fazemos.

Conforme Santaella (2008, p.98) "se julgamento percetivo e abdução têm semelhanças, o que, então, os diferencia? Ambos são igualmente indubitáveis, porque ocorrem. $O$ julgamento de perceção ocorre de modo insistente e compulsivo, enquanto que a inferência abdutiva é menos emotiva." A abdução é uma espécie de juízo e perceção, ambos são exatamente similares até certo ponto do processo, se diferenciam no fim. Rosenthal (apud. Santaella, 2012, p. 109) analisa os dois sentidos do julgamento percetivo: o sentido estreito e o sentido largo. No sentido estreito, há um elemento hipotético, pois o julgamento é uma hipótese de que o conteúdo é o mesmo ou parecido com algum visto antes, ou "assim parece" (W 1, p. 471). No sentido estreito o julgamento percetivo nasce e permanece no impulso originário de modo obsessivo. Já o julgamento percetivo, no sentido largo, também é indubitável em seu impulso, mas diferentemente do julgamento em sentido estreito, o julgamento em sentido largo está aberto a crítica para o contexto interpretativo geral, sendo falível. Nossa vida está cheia de exemplos de situações em que nossa perceção falha. Julgamos ter visto uma coisa, mas, logo depois, nos damos conta de que erramos.

\section{AS CONEXÕES DAS PESQUISAS DE PEIRCE COM O TEMA MÁQUINAS}

A obra de Peirce nos pode ajudar também a enquadrar o fenómeno das máquinas lógicas. Neste sentido, Peirce (1887) toma como exemplo a descrição de uma máquina referida na passagem Viagem à Laputa do livro de Jonathan Swift (2001 [1726], parte III, cap.5), As Viagens de Gulliver.

Na obra Voyage to Laputa existe uma descrição de uma máquina que pode fazer com que a ciência evolua automaticamente. Baseado nessa invenção, até o mais ignorante, com uma condição de empenho racional mínimo e esforço braçal, pode escrever livros em filosofia, poesia, política, direito, matemática, teologia sem ajuda de um gênio ou estudos mais aprofundados (Peirce, 1887, p.165).

Tal máquina seria composta por uma moldura preenchida por uma série de cubos giratórios com palavras escritas em laputanês em cada uma de suas faces. Uma alavanca seria responsável por girar aleatoriamente esses cubos. O resultado, quando apresentasse uma sequência de palavras que fizessem sentido, deveria ser anotado. Essa situação levaria a qualquer um poder ser criativo, tanto a máquina com seus processos, como também uma pessoa sem literacia apenas explorando as possibilidades que a máquina manifesta como resultados. A obra Voyage to Laputa, afirma Peirce, quer "é ridicularizar o Organon de Aristóteles e o Organon de Bacon, 
mostrando o absurdo que é supor que qualquer instrumento possa fazer o trabalho da mente." (Peirce, 1887, p.165) Isso porque uma máquina, assim como o humano, produzindo pensamentos de modo individual, isolados, não conseguiria fazer nada ser criado, nem poderia avançar, evoluir, escolher, pois estariam fechados em si mesmos, levando a uma situação em que a produção de um sentido nunca poderia ter seu processo iniciado, não poderia ser manifestado e nem interpretado por qualquer entidade que seja.

Mas, para Peirce, isso não implica o facto de que as máquinas ou os iletrados não possam raciocinar de algum modo. O exemplo da obra Voyage to Laputa carrega uma situação extrema a qual apenas uma mente altamente complexa pode atender, que é a capacidade de criar e ser original. A despeito disso, é observável a presença de operações lógicas nas máquinas, desde que reconhecendo devidamente sua forma de existência e de limites para os raciocínios que uma máquina pode operar. 0 questionamento de Peirce sobre a natureza de uma máquina se dava também baseado nos "inúmeros motores matemáticos que são compreendidos com utilidades práticas, desde a máquina de somar de Webb até o motor analítico de Babbage, que são também máquinas que performam raciocínios que não são simples." (1887, p.165).

Burks (1978) apresenta ainda um cenário mais amplo das contribuições de Peirce e da presença da sua lógica na existência dos computadores. O autor elenca três factos relevantes que emergiram a partir de suas pesquisas sobre os trabalhos de C. S. Peirce, além dos já referenciados, que estimularam trabalhos desenvolvidos por Burks durante sua participação na construção do ENIAC ${ }^{2}$

3. Em uma carta para Marquand datada de 1886 Peirce sugeriu o uso de relés para a conceção de sua máquina e demonstrou o modo como obter relações "and" e "or" com os relés; 4. Marquand elaborou um diagrama de linhas para a versão de sua máquina lógica mecânica com relés; 5 . Em 1900, Peirce estabeleceu que um computador poderia enumerar todo os teoremas da aritmética axiomática, antecipando com isso a identificação do século 20 dos computadores lógicos (Burks, 1978, p.917)

Peirce, de modo geral, tirou conclusões que abrangem aquilo que está presente em termos de raciocínio nas máquinas lógicas:

O segredo de todas as máquinas com capacidade de raciocínio é bastante simples. É o de que qualquer relação entre os objetos sobre os quais se raciocina está destinada a ser o ponto focal do raciocínio puro; esta mesma relação geral deve poder ser introduzida entre certas partes das máquinas (Peirce, 1887, p.168 apud Nöth, 2007, p.170) 
Peirce afirma que os modos como as máquinas lógicas operam baseiam-se nos fundamentos lógicos da álgebra. "Apenas na álgebra, ao invés de dependermos diretamente das leis da natureza, nós estabelecemos convenções e regras para as relações usadas." (Peirce, 1887, p.168). E compara essa situação a duas outras: primeiro a uma produção de racionalidade de nossa mente descolada de um real externo, quando construímos uma imagem mental determinada sob uma série de condições específicas inerentes ao funcionamento da mente humana e imaginamos o resultado. E a segunda comparação se dá com um aparato de experimentação para física ou química, em que a diferença para a racionalidade da mente está no facto que este não depende dos modos de funcionar do humano para produzir seus resultados, mas sim da razão objetiva incorporada nas leis da natureza, cada qual tendo seu fundamento capaz de operar um processo dentro de seus limites materiais.

Isso decorre de sua observação de que os aparatos de experimentação física e química são regidos por leis incorporadas na realidade. Peirce aponta para uma abordagem não centrada apenas no humano para discutir a questão do raciocínio, deslocando o mesmo da posição de detentor exclusivo da racionalidade e o colocando como mais um aparato em meio à realidade. Provavelmente o aparato de mais alta complexidade entre os conhecidos, mas ainda assim, sem uma exclusividade sobre a questão do pensamento. Aqui se destaca, então, que as máquinas lógicas não estariam restritas apenas às máquinas que seguem os princípios da lógica formal ${ }^{3}$. Peirce aceita também em parte a visão da escola Logicista. Conforme da Costa (1992, p.28) os logicistas defendem a posição de que existem propriedades que constituem uma hipótese sobre o mundo real e, segundo o axioma da redutibilidade, estas devem guiar a validade da lógica.

Existem outras conclusões apontadas por Peirce que merecem destaque para reforçar a compreensão das máquinas lógicas do autor. Peirce apresenta às impotências das máquinas lógicas: "todas as máquinas de raciocínio, isto é, todas as máquinas têm duas impotências intrínsecas. Em primeiro lugar são destituídas de originalidade, de iniciativa; e em segundo não são capazes de identificar seus próprios erros, não podem se corrigir." (Peirce, 1887, p.168)

O autor argumenta que o facto de o raciocínio maquínico estar restrito ao seu cálculo fundante não é um problema de facto, "pois não queremos uma máquina originária." (ibid., p.169). Todo o papel da iniciativa é antes um papel da mente humana, sua principal função. Enquanto às máquinas cabe a função de facilitadora dos processos de raciocínio para as quais foram concebidas. Sobre a segunda impotência, o facto da máquina não poder corrigir a si mesma, isto também não implica uma não racionalidade da mesma. Como exemplo, ele toma a mente do humano sem assistência da objetividade, produzindo um raciocínio todo fundado no imaginário. Para Peirce essa mente também não tem capacidade de autocorreção, porém é dotada de racionalidade simbólica ao estabelecer relações entre seus objetos internos. 
Para o autor as máquinas lógicas são capazes de raciocinar, assim como a mente humana e também os aparatos para experimentações físicas e químicas. São máquinas com diferentes materialidades e razões fundantes: leis do cálculo, leis da mente e leis naturais. O que define o poder de raciocinar é a capacidade dessas máquinas em estabelecer relações entre seus objetos, sejam eles apenas internos ao sistema ou internos e externos ao mesmo, independentemente de sua capacidade de escolher, se corrigir ou de originar. Os limites propostos por Peirce, por aproximação, são sugestões em estado primitivo dos limites das máquinas propostas por Turing (1936). São elas: uma máquina está limitada à finitude de possibilidades combinatórias de sua axiomática fundante, uma máquina não pode corrigir a si mesma e uma máquina não pode verificar seu próprio estado. Como resultado as máquinas estão limitadas nas suas escolhas.

Amini (2008, p.244) reconhece que Peirce antecipou de forma premonitória problemas da metalógica ao discutir que muitas vezes a lógica depende da escolha e de planos deliberados para que possa evoluir e corrigir-se conforme a sua complexidade aumentar. Fonseca (2007, p.62) afirma que a metalógica trata de assuntos relacionados ao valor e aos limites da axiomatização, o nexo entre Lógica e Matemática, o problema da verdade, entre outros. Em um de seus horizontes, e nas figuras de destaque de Hilbert, Gödel e Church, a metalógica trata do externo, preocupa-se com as condições em que se dá o cálculo: a consistência, a completude, a decidibilidade dos sistemas axiomáticos e a independência dos axiomas. Em seus aspectos internos preocupa-se com os significados dos símbolos e da relação dos cálculos relacionados a um mundo particular de objetos. Nesse outro horizonte, destacam-se Tarski, Carnap e Quino.

\section{IDENTIFICANDO E TRATANDO AS FAKE NEWS}

Dentro do grande espírito do tempo de se procurar resolver os problemas sociais, que a sociedade não consegue resolver, sempre através da modelagem dos sistemas tecnológicos e o aperfeiçoamento dos algoritmos, muitas tentativas para se contornar o problema das Fake News têm enveredado por esse caminho. Os algoritmos, como um método dedutivo de cálculo, são capazes de retornar valores exatos a partir de premissas previamente estabelecidas, mas esses processos computáveis não são capazes de escrutinar suas próprias premissas, apenas deduzem a partir delas. Um exemplo é o desenvolvimento de um sistema automático a partir da colaboração entre cientistas da computação do MIT, CSAIL e QCRI (Conner-Simons, 2018). Para conseguir levar adiante o projeto os pesquisadores utilizaram os dados do Media Bias, um site onde os verificadores dos factos são jornalistas e afins. Nesse exemplo as premissas estão sob um continuo escrutínio humano. Estes analisam informações de mais de 2.000 sites de notícias para abastecer a base de dados e se apresentar como sites de Fact Checking. Sem isto as aplicações implementadas sobre esta base de dados operariam com muitas inconsistências. No mesmo artigo os autores apontam ainda os mais de 20.000 profissionais que a rede social Facebook está alinhando para

Ámbitos. Revista Internacional de Comunicación | ISSN: 1139-1979 | E-ISSN: 1988-5733, №. 46. (2019) 
tratar a sua base de dados. Em Portugal existe uma iniciativa similar para a verificação das Fake News desempenhada pelo site Poligrafo (Ferreira, 2018). São exemplos de escolhas redacionais baseadas na colaboração com específicos projetos computacionais, algo que testemunha da crescente necessidade de integrar inteligência matemática e competências socioprofissionais dentro do contexto sociotécnico atual.

Vimos que, apesar da engenharia dos algoritmos estar na base de produção de conteúdos massivos e ao mesmo tempo personalizados, ela não aparenta ser o principal agente de disseminação. Aos algoritmos escapa o problema da escolha. Problema esse que ao jornalista ou a humanidade em geral não deveria escapar. Tanto daqueles que lidam com as bases dos sistemas informacionais quanto daqueles que lidam com sua superfície. Um algoritmo não é capaz de julgar para além das premissas que estão na base dos seus dispositivos constituintes e também não interpreta seu resultado final, diferentemente dos processos cognitivos de um humano.

Os limites dos programas de computador, baseados em fórmulas finitas para que funcionem, não podem lidar com números infinitos, apesar de se poderem manifestar operantes como tal. Seguindo os estudos da matemática formalista (ver da Costa 1992, p.49) ${ }^{4}$, existe uma grande quantidade de números infinitos convencionados pelo humano, porém, especificando mais detalhadamente os números computáveis propostos por Turing (1936, p.1), estes "são apenas os números racionais inteiros, irracionais finitos e alguns especiais". A maioria dos números dos conjuntos reais e números do conjunto imaginário que os humanos estão aptos a calcular, por exemplo, as máquinas não os computam. Em outras palavras, o paper seminal de Turing (ibid.) descreve o que é o conjunto dos números computáveis. Processos computacionais operam dentro desses limites. Já a matemática como ciência formal descreve uma série de outros conjuntos numéricos que o ser humano pode calcular. Este tem um escopo bastante mais amplo que o conjunto dos números computáveis. É um apontamento que vai no cerne da grande diferença entre os processos cognitivos humanos e mecânicos destacando a perspetiva das capacidades de cálculo de cada um, mas que não destaca uma distância ainda maior, pois ambos ainda estão, nessa perspetiva, presos ao campo dedutivo do pensamento.

Para avançar essa discussão, entramos então em assuntos de escopo meta computacional, na medida em que a base conceitual de toda computação não dá conta de criar um grande programa geral, um procedimento efetivo, que possa ser aplicado a qualquer programa e verificar se o mesmo está procedendo de maneira finita. Para parar uma máquina de Turing, outra máquina era necessária. Tal explicação foi demonstrada por Turing, 1936, na sua "demonstração sobre o teorema da parada da máquina." (Teixeira, 1998, p. 153) 
Turing conseguiu construir uma máquina... cujas funções poderiam ter descrições finitas, mas que não poderiam ser computadas num sentido finito... Turing chamou a configuração da parada "de circular" e das configurações que continuam procedendo indefinidamente "de livres de circularidade", e demonstrou que a não solvência do problema da parada implica na não solvência de uma ampla classe de problemas similares, incluindo o problema da escolha. (Dyson, 2012, p.248249)

Mais recentemente muito se tem dito a respeito do chamado machine learning. Este é um método de programação onde o computador executa uma tarefa pré-determinada que é a de aprender. Ela pode compor, por exemplo, uma das vertentes de um outro sistema operacional, que é o da rede neural ${ }^{5}$. A rede neural tem dois modos de funcionamento: aprendizagem e execução. No primeiro caso os exemplos são apresentados à máquina de modo que a mesma construa o seu próprio banco de dados. São exemplos o reconhecimento de imagens estáticas ou dinâmicas, textos ou áudios. Esse banco de dados é composto, portanto, pelas imagens, os textos e áudios, mas também pelas interpretações prévias feitas por especialistas com base nas associações testadas entre inúmeros textos, imagens, áudio e relativos contextos. Passada a etapa de aprendizagem a máquina pode entrar no modo de execução, isto é, poderá dar um feedback ao que lhe for apresentado/solicitado (sempre com base nas associações armazenadas na sua base de dados). Por exemplo, a fotografia de um carro numa paisagem. Caso o cadastrado no banco de dados da máquina possua exemplos suficientes dessa entidade em diferentes contextos, é possível que ela identifique um carro também em um novo contexto ou paisagem (ou aponte ainda se a paisagem tem ou não um carro). Os índices de acerto se aproximam dos índices humanos. Enquanto o especialista auxilia na construção das interpretações iniciais, o programador tem o foco em determinar a topologia da rede neural, ou seja, quantas camadas de neurónios, quantas entradas e quantas saídas são necessárias para chegar aos resultados pretendidos.

Tal máquina conexionista possui ainda uma autonomia bastante restrita, pois reduz o aprender a apenas realizar uma inferência lógica: em modo "execução", "vê" uma imagem e afirma: "a imagem contém um carro", ou "a imagem não contém um carro". Nenhuma dessas inferências é capaz de alterar seu modo de agir no mundo. Na vertente da "aprendizagem" os hábitos da máquina alterados são apenas aqueles que se referem às suas capacidades de execução e não sobre suas capacidades de escolha sobre o que executar. O operador humano pode alternar entre os dois modos. Portanto, do ponto de vista da autonomia e escolha, a máquina ainda depende do operador humano externo. Quando a máquina está em modo "execução", sua ação é inteiramente determinada pelos parâmetros internos produzidos na modalidade "aprendizagem", onde a máquina segue um roteiro guiado pelo humano do qual não pode fugir.

Ámbitos. Revista Internacional de Comunicación | ISSN: 1139-1979 | E-ISSN: 1988-5733, №. 46. (2019) 
Podemos até atribuir capacidades indutivas a um algoritmo, ao aliar análise estatística entre suas funções constituintes, mas ainda assim esta será uma indução dentro de um campo dedutivo previamente estabelecido, racionalmente circular. Portanto este algoritmo não será capaz de uma abdução genuína, pois não pode escolher, não pode alterar suas premissas e nem escrutinar, não consegue sair deste ciclo para o qual foi programado. Todavia, enquanto um algoritmo não pode operar para além das suas premissas constituintes, um ser humano pode basear-se apenas nas suas emoções e preconceitos para aderir a crenças falaciosas e divulgá-las. Nesse sentido, um ser humano também estaria limitado, mesmo que por uma via distinta do algoritmo, no seu processo de decisão. Mas esta limitação é cultural, portanto poderia ser, também, o resultado dum pensamento crítico socialmente cultivado. Desse modo, a lacuna que necessita ser preenchida é aquela da literacia, isto é, a formação cultural e reflexiva dos humanos, jornalistas, no seu processo crítico de identificação e avaliação do objeto com o qual se relaciona.

Quando nos processos de análise das informações falta tal competência reflexiva, o ser humano parece mais vulnerável aos condicionamentos externos, como os computadores são-no às instruções internas. Ambos não fazem escolhas, o primeiro por causa das suas limitações mecânicas e o segundo pelos seus enviesamentos emocionais e enraizadas crenças não científicas. Para que tal situação seja evitada, então se sugere que os processos da lógica crítica de C. S. Peirce sejam promovidos e operacionalizados como técnica de apoio na identificação de Fake News, a saber:

O jornalista deve necessariamente passar por um estado abdutivo em seu sentido estreito quando se depara com um facto particular. Ele deve buscar as suas ramificações, os seus aspetos mais gerais. O primeiro julgamento mediado pela perceção particular tem um caráter ainda bastante emocional, portanto a potencial notícia deve ser tomada com grande cuidado para que as crenças não científicas não guiem o processo. O próximo passo é submeter o facto às inferências necessárias, ou dedutivas e prováveis, ou indutivas. Isso leva à maturação do pensamento e da reflexão sobre a notícia. Nesse avanço do processo de pesquisa o jornalista imagina hipóteses a partir do facto e a busca subsequente se deve direcionar a um corpo formal de conhecimento sobre o objeto jornalístico. O intuito é o de verificar aquilo que já se sabe acerca do objeto referido, ampliando e enriquecendo o campo de possibilidades inicialmente concebido, buscando sentidos coerentes para além de juízos apenas particulares. Neste ato extraem-se mais elementos de outras fontes credíveis. A narrativa ganha corpo e consistência. No terceiro passo se devem buscar e averiguar indicadores sobre o objeto, caso o mesmo já tenha sido testado, ou buscar um modo de testar os elementos obtidos a ver se têm correspondências com a realidade. São provas que se obtêm a partir de testes práticos e significativos. Este ato visa certificar se a realidade do corpo formal visitado ainda é válida, se precisa de atualização ou se está 
inválida. Todo jornalista que se dispuser a seguir essas etapas na construção de uma narrativa jornalística, ou na análise de uma notícia, a partir de um facto vivido ou compartilhado, minimizará a possibilidade de cometer e reproduzir erros ligados com a disseminação de notícias falsas. Essas etapas permitem ao jornalista blindar-se contra crenças internas não desejadas, previnem a adoção de narrativas desatualizadas ou falsas e permite ainda a elaboração de uma nova narrativa, com razoável correspondência com a realidade e ao mesmo tempo com razoável coerência interna, contribuindo com a prevenção e combate às notícias falsas. Ao mesmo tempo, auxiliariam o processo de revisão e reformulação dos conteúdos e das premissas operacionais dos sistemas computacionais que intervêm dentro deste contexto de disseminação das notícias.

\section{CONSIDERAÇÕES FINAIS}

Ainda que se saiba como os jornalistas profissionais apliquem os seus próprios conhecimentos no sentido de garantir a credibilidade dos seus serviços informativos, a perspetiva aqui apresentada aponta para corroborar os instrumentos críticos e reflexivos não apenas de quem trabalha nos sectores da informação e comunicação contemporânea, como também dos leitores/recetores/consumidores/distribuidores de notícias online. É esperado que o processo ainda assim seja falível, porém é uma falha distinta daquelas geradas pela perceção hodierna e predominantemente baseada na aceitação/rejeição instintiva dos conteúdos online. Pretende também ser uma falha distinta daquela atrelada aos limites ou as distorções intencionais que podem refletir-se no design e funcionamento dos algoritmos. Apesar de tudo, acarreta a diferença relevante de usar aquilo que o ser humano tem de mais precioso, que é a qualidade de poder fazer escolhas a partir de um pensamento emocional que sofreu as etapas críticas necessárias antes de ser autorizado (ou não) a aceitar e multiplicar novos conhecimentos.

\section{Notas}

1 Pluta, A. (2016) Trump Supporters Appear to Be Misinformed, Not Uninformed, in https://fivethirtyeight.com/features/trump-supporters-appear-to-be-misinformed-notuninformed/(visitado em 29/06/18)

${ }^{2}$ A computação eletrônica teve seus primórdios entre 1936 e 1939 através de John Vincent Atansoff e Johjn Berry através da máquina $A B C$. Esta era dedicada à solução de conjuntos de equações lineares na Física. Esta máquina carregava os conceitos fundamentais dos computadores eletrônicos: a unidade aritmética eletrônica e a memória de leitura e gravação. Nos EUA, início da II Guerra Mundial, surgiu o ENIAC, com destaque para os pesquisadores Eckert, circuitos eletrônicos, John Mauchly, físico, e Herman H. Goldstine, matemático. Tratavase de uma máquina de 18.000 válvulas programável. Sua programação era feita por fios e chaves. Os dados para serem processados vinham de um cartão perfurado.

Ámbitos. Revista Internacional de Comunicación | ISSN: 1139-1979 | E-ISSN: 1988-5733, №. 46. (2019) 
${ }^{3}$ De acordo com da Costa (1992, p.49) "o formalismo nasceu das vitórias alcançadas pelo método axiomático." No método axiomático Hilbert propôs demonstrar a coerência da aritmética e estender a mesma para os demais sistemas. Seu sistema formal pretendia utilizar argumentos finitos. Para tal criou uma linguagem formal e um conjunto de regras formais de inferências. Acreditava que poderia ser concebido um número suficiente de passos para que toda demonstração correta de um teorema clássico pudesse ser representada por uma dedução formal com cada passo mecanicamente verificável; desenvolveu uma teoria das propriedades combinatórias desta linguagem formal e destas regras; e propôs demostrar que, dentro deste sistema, não podiam existir contradições, como visto também nos fundamentos da escola formalista. Em síntese, Hilbert buscava um sistema formal completo e consistente. A doutrina formalista influencia em grande escala os trabalhos de Turing. Outro destaque desta escola foi Von Neumann.

${ }^{4}$ Da Costa apresenta o intuicionismo, o logicismo e o formalismo como correntes filosóficas distintas que discutem o que é a Matemática. Há entre elas aproximações e distanciamentos e uma não exclui a outra. $O$ intuicionismo, fundamentado no construtivismo, mostrou quais conhecimentos matemáticos podem e quais não podem ser construídos partindo de ideias intuitivas. O logicismo mostra as intersecções da Matemática com a Lógica. E o formalismo estabelece a Matemática como a ciência dos sistemas formais, dedutivos.

${ }^{5}$ Boden (1988, p.45) define o conexionismo como a modelagem de sistemas de processamento em paralelo que performam computação de modo cooperativo, "baseado em interações locais simultâneas de unidades interconectadas." Cita como exemplo trabalhos pioneiros como os de D. O. Hebb (1949), O. G. Selfridge (1959), F. Rosenblatt (1958). Em linha com as abordagens sistêmicas, que sempre circundaram o campo da inteligência artificial, os conexionistas entendiam que a mente era um sistema dinâmico, configurada por um conjunto de processos causais através das quais as unidades se excitam ou inibem, sem se dispor apenas de símbolos e regras estáticas para manipulá-los, como compreendiam os cognitivistas. Sonhava-se que um conjunto de neurônios artificiais formalizassem os processos da cognição, situando o cérebro como o substrato físico dessa rede e a mente como um correspondente abstrato.

\section{Referências}

Aminl, Majid. (2008). Logical Machines: Peirce on psychologism. Disputatio, Vol.Il, $n^{\circ} 24$, May.

Blaug, M. (1997). The Methodology of Economics or how economists explain. Cambridge: Cambridge University Press.

Boden, A. Margaret. (1988). Computer Models of Mind: Computational approaches in theoretical psychology. Cambridge. Cambridge University Press.

Bolton, D. M., \& Yaxley, J. (2017). Fake news and clickbait - natural enemies of evidence-based medicine. BJU International, 119, 8-9. https://doi.org/10.1111/bju.13883

Broussard, Meredith. (2018). Artificial unintelligence. How computers misunderstand the world. Cambridge, MA: MIT Press.

Ámbitos. Revista Internacional de Comunicación | ISSN: 1139-1979 | E-ISSN: 1988-5733, №. 46. (2019) 
Burch, R. "Charles Sanders Peirce", The Stanford Encyclopedia of Philosophy. Fall 2001 Edition, Edward N. Zalta. http://plato.stanford.edu/archives/fall2001/entries/peirce.

Burks, W. Arthur. Burks. (1978). Bulletin of the American Mathematical Society. Volume 84, number 5, p.913-918. September.

Conner-Simons, Adam. Detecting fake news at its source Machine learning system aims to determine if an information outlet is accurate or biased. MIT News 04-Out-2018. http://news.mit.edu/2018/mit-csail-machine-learning-system-detects-fake-news-fromsource-1004

Da Costa, Newton. (1992). Introdução aos fundamentos da matemática. Ed. Hucitec. São Paulo.

Dyson, George. (2012). Turing's Cathedral: the origins of digital universe. New York. Pantheon Books.

Fake News. Oxford Dictionary. Disponível em https://en.oxforddictionaries.com/definition/posttruth. Acesso em 10 outubro de 2018.

Ferreira, Victor. Nasceu o Polígrafo, um jornal para detectar mentiras. Jornal Público de Portugal 06-Nov-2018. https://www.publico.pt/2018/11/06/economia/noticia/nasceu-poligrafojornal-detectar-mentiras-1850140.

Gala, A. C. O. S. (2015). Bases fundamentais para construção de uma ferramenta automática de assessment de personalidade. Tecnologia Educacional, Associação Brasileira de Tecnologia Educacional. v. 31, p. 6-16.

Hands, D.W. (2001). Reflection without Rules, Economic Methodology and Contemporary Science Theory, Cambridge University Press, Cambridge.

Harari, Yuval Noah. (2018). 21 Lições para o Século XXI. Penguin Random House, Reino Unido.

Hoover, K., D. (1994). "Pragmatism, Pragmaticism, and Economic Method" in Contemporary Issues in Economic Methodology, Roger E. Backhouse, editor. London: Routledge.

Marcos Recio, J. C., Sánchez Vigil, J. M., \& Oliveira Zaldua, M. (2017). La enorme mentira y la gran verdad de la información en tiempos de la postverdad. Scire.

McCrae R. Robert, John P. Oliver. (1991). An Introduction to the Five-Factor Model and Its Applications. National Institute on Aging. NIH.

Nichols, T. (2018) A Morte da Competência, Lisboa, Quetzal.

Nöth, Winfried. (2007). Máquinas Semióticas. Computação Cognição Semiose. UFB, 1859-183.

Peirce, C. S. (1877). The Fixation of Belief, Popular Science Monthly 12, November, 1-15.

Logical Machines. (1887). American Journal of Psychology. 1.1, S. 165-167. 
Collected Papers, Hartshorne, Weiss, and Burks (eds.), 8 vols. Cambridge: Harvard University Press, 1931-1958. Citado como CP seguido pelo número do volume e números de parágrafos. MS e $L$ referem-se aos manuscritos não publicados e paginados pelo ISP.

(1958). Selected Writings (Values in a Universe of Chance), ed. Philip Wiener, Dover Publications, New York.

(1982). Writings of Charles S. Peirce. A Chronological Edition, Fisch et al. (eds.), Bloomington: Indiana University Press. Citado como W seguindo do número do volume.

(1992). The Essential Peirce, Selected Philosophical Writings, Indiana University Press.

Pluta, A. (2016) Trump Supporters Appear to Be Misinformed, Not Uninformed, em FiveThirtyEight.com (https://fivethirtyeight.com/features/trump-supporters-appear-to-bemisinformed-not-uninformed/)

Rosenthal, S. (2005). Peircean Phaneroscopy: The pervasive role of abduction. Semiotica 1531/4, 299-307.

Santaella, Lucia. (2004). O Método Anticartesiano de C.S. Peirce. São Paulo: Editora UNESP.

(2012). Percepção. Fenomenologia, ecologia, semiótica. 1. ed. São Paulo: Cengage Learning.

(2008). Cognitio, São Paulo, v. 9, n. 1, p. 93-110.

(2016). Temas e dilemas do pós-digital. A voz da política. São Paulo: Paulus.

(2018). A pós-verdade é verdadeira ou falsa?. São Paulo. Coleção Interrogações.

Sunstein, C.R. (2017) \#Republic. Divided Democracy in the Age of Social Media. Princeton: University Press.

Teixeira, João Fernandes. (1998). Mentes e Máquinas: uma introdução à ciência cognitiva. Porto Alegre: Artes Médicas.

Turing, Alan. (1936). On Computable Numbers, with an Application to the Entscheidungsproblem. Proceedings of the London Mathematical Society, ser. 2, vol. 42, 230. 


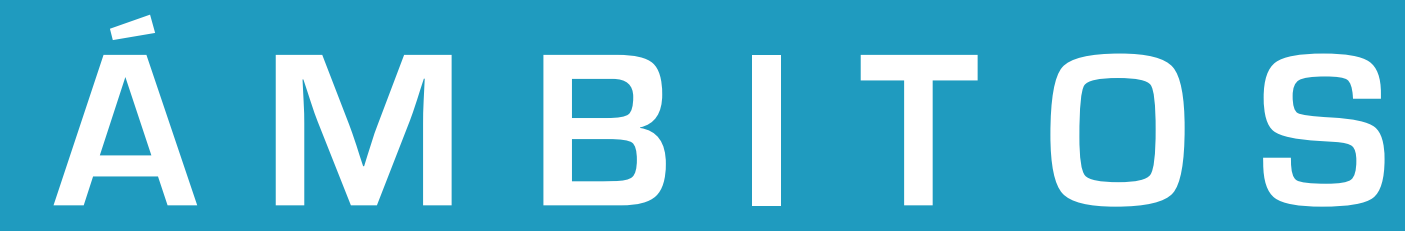

ISSN: 1139-1979 | ISSN digital: 1988-5733 | Depósito Legal: SE-1493-98

Revista Internacional de Comunicación editada por el Grupo de Investigación en Estructura, Historia y Contenidos de la Comunicación(GREHCCO) de la Universidad de Sevilla.

\section{ambitoscomunicacion@us.es}

http://institucional.us.es/ambitos

@RevistaAmbitos 